\title{
Occupational therapy services and perception of integration of these at Primary Healthcare Level in South Africa
}

\author{
Anthony Jejelaye, BMR OT (OAU); MSc. OT (Wits). http://orcid.org/0000-0002-8352-4525 \\ Occupational Therapist, City Rehabilitation Centre, Benin City, Nigeria \\ Post-graduate student, Occupational Therapy Department, Faculty of Health Sciences, School of Therapeutic Sciences, University \\ of Witwatersrand.
}

\section{Lebogang Maseko, BSc OT (Wits), MPH Health Systems and Policy (Wits). http://orcid.org/0000-0002- 6|26-5104}

Lecturer Occupational Therapy Department, Faculty of Health Sciences, School of Therapeutic Sciences, University of Witwatersrand.

Denise Franzsen, BSc OT (Wits), MSc OT (Wits), DHT (Pret) PhD. http://orcid.org/0000-000I-8295-6329

Sessional Senior Lecturer, Occupational Therapy Department, Faculty of Health Sciences, School of Therapeutic Sciences,

University of Witwatersrand.

Background: Literature indicates that access to rehabilitation services in South Africa is limited. Recent policy documents by the National Department of Health related to disability and rehabilitation propose the integration of occupational therapy services in primary healthcare (PHC). However, the implementation strategies concerning integration are not clear as there is inadequate evidence locally on the occupational therapy service provision in $\mathrm{PHC}$ even though there is growing evidence internationally.

Purpose: This study sought to determine the services provided by occupational therapists in PHC and to explore the perceptions of the occupational therapists on the integration of occupational therapy services within the PHC reengineering streams of the National Health Insurance (NHI).

Method: A two-phase explanatory sequential mixed method strategy was utilised in this study. A quantitative survey was sent to members of the occupational therapy professional association and an organisation of professionals providing rehabilitation services in rural communities. Qualitative data were then collected using semi-structured interviews with five therapists who completed the survey.

Findings: Findings from this study showed there is increasing alignment of occupational therapy services in PHC with the communitybased rehabilitation (CBR), the Social Model, the International Classification of Functioning, Disability and Health (ICF), and the Medical Model using client self-management and case-management intervention approaches. The majority of occupational therapists are currently based in district hospitals (42\%), community health centres (I6\%), community organisations (8\%), and clinics (8\%). Those working in the community indicated they work in a multidisciplinary team (MDT). They also use PHC service delivery models to manage people with disabilities (PWDs). Occupational therapists in PHC have a strong perception of their relevance in the PHC reengineering streams, despite the numerous barriers and few facilitators to the integration of occupational therapy services in the $\mathrm{PHC}$ reengineering streams of the $\mathrm{NHI}$.

Conclusion: The perception of the study participants is that occupational therapy service integration in the PHC reengineering streams will lead to improved healthcare. However, they are also of the opinion that integration will not happen without advocacy from occupational therapists or occupational therapy being adequately supported in PHC.

Key words: Occupational therapy, primary health care re-engineering, integration, National Health Insurance, universal health coverage

\section{INTRODUCTION}

There are an estimated 4.2 million people with disabilities (PWDs) ${ }^{\prime}$ in South Africa, resulting in a prevalence of $7.5 \%{ }^{2}$. Access to occupational therapy and other rehabilitation services for PWDs in South Africa is limited due to factors such as the location of health care services, inadequate rehabilitation workforce, a two-tiered health system (well-funded private-underfunded public health care dichotomy), transportation challenges, as well as poor policy implementation regarding disability and rehabilitation ${ }^{3,4}$. These limiting factors persist despite the existence of recent policy documents published by the National Department of Health (NDoH) related to healthcare, disability, and rehabilitation services ${ }^{3}$. Both the Framework and Strategy for Disability and Rehabilitation Services in South Africa 20 I5-2020 (FSDRSA) ${ }^{5}$, the National Health Insurance (NHI) White Paper $2017^{6}$, and the NHI Bill 20197, propose the integration of rehabilitation services within the primary healthcare framework in South Africa in tandem with the primary healthcare $(\mathrm{PHC})$ reengineering process ${ }^{8}$.

Although PHC reengineering was extended to include rehabilitation professionals such as occupational therapists ${ }^{8-10}$, the implementation strategies of the policies are not entirely clear ${ }^{1,12}$. The lack of clarity is evidenced by the absence of detailed steps in implementing the policy. The lack of clarity is compounded by inadequate local evidence of the occupational therapy service provision in $\mathrm{PHC}$ even though there is a growing evidence for this role internationally ${ }^{12-15}$ Thus, at this point in South Africa, when policies and frameworks in relation to disability and rehabilitation in $\mathrm{PHC}$ are in the initial phases of implementation, it is important to fill the knowledge gap by providing an evidence base for the integration of and provision of occupational therapy services in $\mathrm{PHC}^{16}$.

Integration in this study is operationally defined as the presence of occupational therapists working in the inter-professional PHC 
teams in keeping with the $\mathrm{PHC}$ reengineering streams of the $\mathrm{NHI}$ which include clinical specialist support teams, school health services, municipal ward-based $\mathrm{PHC}$ outreach teams, and contracting or purchasing the services of private health practitioners. To support the integration of occupational therapy services in $\mathrm{PHC}$ this study sought to explore how services are provided by occupational therapists in PHC. The perceptions of occupational therapists on the integration of occupational therapy services within the PHC reengineering streams of the $\mathrm{NHI}$ were also explored ${ }^{17}$.

\section{LITERATURE REVIEW}

\section{Rehabilitation at a primary health care level in South Africa}

Rehabilitation service provision is an issue especially in the low and middle-income countries, where $80 \%$ of the global population of the one billion PWDs live ${ }^{18}$. Persons with disabilities have been shown to have a lower quality of life as a result of poorly addressed impairment, activity limitations, and participation restrictions ${ }^{18}$. Attitudinal, political, financial, communication, physical, and health system barriers also impact the lives of PWDs s $^{19,20}$. In South Africa, some of the major limitations confounding PWDs in accessing quality and adequate occupational therapy services are the historical fragmentation of the health sector, the two-tiered private-public contrast in healthcare delivery ${ }^{21}$ as well as the health care staffing crises $^{22}$.

The South African NDoH has proposed a national health insurance policy ${ }^{6}$ to address these limitations, in line with the international move towards achieving universal health coverage (UHC) by $2030^{10,23}$. The $\mathrm{NHI}$, through primary healthcare reengineering, aims to address the current inadequacies in the South African health system such as the private-public sector inequity, maldistribution of staff, and challenges in accessing healthcare services. Primary healthcare reengineering thus forms a key pillar of the $\mathrm{NHI}$ with a four-stream approach within the District Health System (DHS) as the established medium of delivery ${ }^{24}$. The four streams include clinical specialist school, municipal ward services as well as private health practitioner services including occupational therapists, at non-specialist level ${ }^{8-10}$.

Since the last stream is the only $\mathrm{NHI}$ document published in $2017^{6}$, which briefly refers to rehabilitation and occupational therapy services, it remains to be seen how equity would be achieved in essential rehabilitation services such as occupational therapy within this policy framework. Local studies reveal limited provision of occupational therapy and other rehabilitation services in South Africa ${ }^{12}$, where disability is increasing due to a larger ageing population, as well as higher prevalence of chronic, and non-communicable diseases'. This limited provision of occupational therapy services will persist without the integration of occupational therapy and other rehabilitation services in the mainstream health care programmes, especially at $\mathrm{PHC}$ level if the $\mathrm{NHI}$ is implemented ${ }^{25}$.

International literature has provided evidence and service delivery models that can be followed when providing occupational therapy services in an integrated manner at $\mathrm{PHC}$ level. According to $\mathrm{McC}$ oll et al. ${ }^{26}$, six models have been used and these include community-based rehabilitation (CBR), shared care, case management, client self-management, clinic-based care, and community outreach $^{27-29}$. In South Africa, very few of these models are considered in relation to occupational therapy in the $\mathrm{NHI}$, which has an emphasis on the curative view of health care in service planning and provision, and which may continue to overlook rehabilitation as a component of PHC.

Of these service delivery models, CBR (through the CBR matrix $)^{27}$, is of particular importance as the principles of $C B R$ resonate with those of PHC, in that the focus of both is on the accessibility of healthcare for everyone including those who have difficulty in accessing care. Community-based rehabilitation also supports some of the disability models, including the social mode ${ }^{30}$ human rights model $^{31}$, biopsychosocial model ${ }^{32}$ and the International Classification of Functioning, Disability and Health $(\mathrm{ICF})^{33}$, which are the lenses through which disability is viewed by society. These models provide insight into the approach taken by healthcare providers in addressing disability ${ }^{34-36}$ and are used in occupational therapy to provide services.

However, studies still report the predominant use of the medical model ${ }^{34}$ including in occupational therapy practice at $\mathrm{PHC}$ level in South Africa which is contrary to the CBR approach ${ }^{3}$. The medical model focusses on the underlying impairment(s) suffered by an individual, which differentiates them from other members of society ${ }^{34}$. This also dictates a personalised approach to treatment to alleviate or remediate the impairments. The oldest model conceived prior to the $18^{\text {th }}$ century Western Industrial Revolution - the moral mode ${ }^{35}$ still persists in very traditional societies, even some in South Africa, and is used to explain illness or disability and also needs to be considered when providing services. This model is closely linked to cultural and religious beliefs and views disability as a result of sin, chastisement for negative deeds, or as a spiritual test ${ }^{35}$.

Even so, it is not the use of a model which conflicts with CBR, but rather the multi-sectoral approach that $C B R$ requires, that has been sighted as the biggest challenge to the delivery of rehabilitation services at a PHC level ${ }^{27}$. Although the $\mathrm{NDoH}$ in South Africa, through the ratification of the National Rehabilitation Policy 2000 $(\mathrm{NRP})^{36}, \mathrm{FSDRSA}^{5}$, and United Nations Convention on the Rights of Persons with Disabilities (UNCRPD) $2006^{37}$, recognises CBR as a service delivery strategy, the implementation of these policies has been poor ${ }^{38,39}$. This is because both the Ministries of Health and Social Development are responsible for the CBR-based disability and rehabilitation services and there appears to be hardly any collaboration between the two ministries ${ }^{40}$. Furthermore, due to a poor policy implementation culture in South Africa, policy documents that address disability and rehabilitation are in existence in the country but are largely unimplemented ${ }^{41}$.

This limited access to occupational therapy and other rehabilitation services results in the majority of the rehabilitation needs of individuals not being addressed. However by empowering them to minimise the barriers they encounter and involving their family members in their home rehabilitation programmes this situation can change ${ }^{13,42}$. Results from a study in Ghana by Dalinjonget al. ${ }^{43}$ showed that equity in healthcare services can be achieved in an African country with $\mathrm{NHI}$ and a service coverage of up to $80-90 \%$. Similar success is achievable in South Africa with the integration of occupational therapy services in the $\mathrm{PHC}$ reengineering streams of the NHI. The presence of occupational therapists working in the inter-professional PHC team has been documented both locally and internationally resulting in increased access to immediate and collaborative needs-based care, while also saving costs ${ }^{12,14,15}$. Thus, occupational therapy in South Africa should form an essential component of PHC services, based on the CBR framework as highlighted in position statements from both national and international Occupational Therapy Associations ${ }^{44,45}$.

\section{METHODS}

\section{Study Design}

A two-phase explanatory sequential mixed method design was used with data from the first quantitative phase guiding the second qualitative phase, both of equal weights ${ }^{46}$. The first phase was a nationwide cross-sectional descriptive quantitative survey to establish how occupational therapy services are delivered in PHC in South Africa. The second phase was a qualitative study using in-depth interviews to build on the findings in Phase I about occupational therapists' perceptions on the integration of occupational therapy services in the $\mathrm{PHC}$ reengineering streams of the $\mathrm{NHI}$. In this study, data were integrated by connecting the data analysis from phase one (quantitative) to inform questions and probing in phase two (qualitative). The connection was used to achieve a $I+I=3$ integration framework ${ }^{47}$ by leveraging on the strengths of both the qualitative and quantitative methods integration framework, an interpretation of more than the individual component methods was achieved ${ }^{47}$. 


\section{Population and Sampling}

The target population/participants were occupational therapists working at the PHC level in South Africa. Only the data from occupational therapists who indicated that they have/had experience with PHC were included in the analysis. A QUAN-QUAL sampling technique using probability sampling in the quantitative phase followed by purposive sampling in the qualitative phase with participants recruited from those in the quantitative phase was used ${ }^{48}$.

The electronic survey was sent out to all members of the Occupational Therapy Association of South Africa (OTASA) in an all-member mailing and therapists who have experience with PHC were asked to respond. The survey was also distributed through the Rural Rehab South Africa (RuReSA) platform. Lastly, a snowball sampling technique was used to recruit participants nationwide by asking therapists who received the survey to forward it on to colleagues who had not received it. With the assumption that less than $10 \%$ of the occupational therapists in South Africa are working at the PHC level based on literature ${ }^{3,49}$, a sample size of 75 was needed to represent the population with a $5 \%$ margin of error as recommended by Bartlett, et al. ${ }^{50}$.

\section{Data Collection and Management}

The survey utilised in the first phase of this study was adapted from an open access Canadian survey study on a national survey of occupational therapy in primary care by Donnelly et al. ${ }^{14}$. The survey contained I 7 closed and seven open-ended questions. The closed questions captured aspects such as the participants' demographic information, the nature of the occupational therapy services that they provide, and the service delivery model that they utilise. The open-ended questions of the survey captured the perceptions of occupational therapists on the perceived barriers and facilitators for integration of current occupational therapy practice in PHC. The survey was developed in an electronic format using Research Electronic Data Capture (REDCap) ${ }^{5 !}$.

The survey was piloted with three occupational therapists who were subject matter experts (SMEs) experienced in PHC, for content validity and ambiguity to address emergent issues before data collection commenced. Subsequently, the survey was then modified by removing or rewording some questions in terms of therapists' qualifications, the types of services offered and future services to be offered. Based on the recommendations of the SMEs, the questionnaire was deemed suitable for the local South African context, with a content validity index of $89 \%$.

Following completion of the electronic survey, the participants were given the option to indicate their willingness to participate in the second phase of the study and participants were purposively selected for Phase 2 of the study. The researcher attended a course on qualitative research methods and the research assistant was also trained before the second phase commenced. The second phase of the study explored the responses from the open-ended questions of the survey through in-depth interviews. In the event of failure to carry out a face-to-face interview with any of the participants, Skype and WhatsApp interviews were carried out and audio-recorded. Five interviews were conducted in English and audio-recorded at which point data saturation was reached. A semi-structured interview format was chosen as it provided room for clarity of concepts that may have loose associations or lack of focus. The questions were also flexible to accommodate probing and emergence of new ideas. Field notes were taken by the research assistant during the interviews so as to document observed non-verbal communication of the participants which the audio-recorder may not capture.

\section{Data Analysis}

The survey data of participants were presented using descriptive statistics on REDCap ${ }^{51}$ and Statistica $V 13-2^{52}$. The responses provided for each of the open-ended questions were analysed using frequencies and content analysis. This analysis served as a basis for the refinement of the in-depth interview questions that were used in the second phase of the study.
Data collection and analysis took place concurrently for the second phase of the study. All interviews were transcribed verbatim and field notes were typed. The researcher read and edited all the transcripts to get a broad overview of the information and to ensure the accuracy of the transcriptions. Afterwards, individual transcripts were analysed manually using thematic content analysis to develop codes, which were then categorised into categories (sub-themes) and themes ${ }^{46}$. Finally, interpretation of data was done based on meanings that emerged from the themes. Results were presented comprehensively under separate headings for each analysis. Finally, trustworthiness was ensured, as recommended by Curtin and Fossey ${ }^{53}$ using member checking, note-taking, keeping a reflexive journal, representation of population by participants, audit trail, inquiry audit, checking and confirming of emergent themes and categories by the co-authors, and triangulation of data sources to ensure credibility, dependability, transferability, and confirmability ${ }^{53}$.

\section{Ethical Consideration}

Ethical approval was sought and received from the University of the Witwatersrand's Human Research Ethics Committee (Medical) (MI80819). For the first phase, the electronic survey was accompanied by a study information sheet. Responding to the survey and submission on REDCap signified consent to participate in the study. Participants who opted to be included in the qualitative stage of the study were provided with an information sheet and were requested to sign informed consent as well as grant permission to be audio-recorded during the interview. The participants were informed that participation was voluntary, and they could withdraw at any point in the study. Furthermore, anonymity and confidentiality were ensured by not requiring identifying data on the survey and not including participants' names in the quantitative and qualitative analysis.

\section{RESULTS}

\section{Phase I - Current occupational therapy service provision in primary healthcare}

Seventy-two responses from the survey were received, and all the 72 returned survey responses were analysed because they met the inclusion criteria of having experience in $\mathrm{PHC}$, although the specific responses for each question differ as some responses were not fully completed. The survey participants were predominantly female (91\%), mostly in their 20s and 30s. Although all the participants indicated they had/have experience with $\mathrm{PHC}$ ( $\mathrm{I}-35$ years), most had 5 years or less of work experience with experience in PHC after their year of community service. The descriptive analysis of the quantitative phase of the study showed that occupational therapists at PHC level work more in the urban $(68 \%)$ than rural (32\%) areas. The majority of participants were currently based in district hospitals (42\%) providing outreach services, community health centres (16\%), community organisations (8\%), and clinics

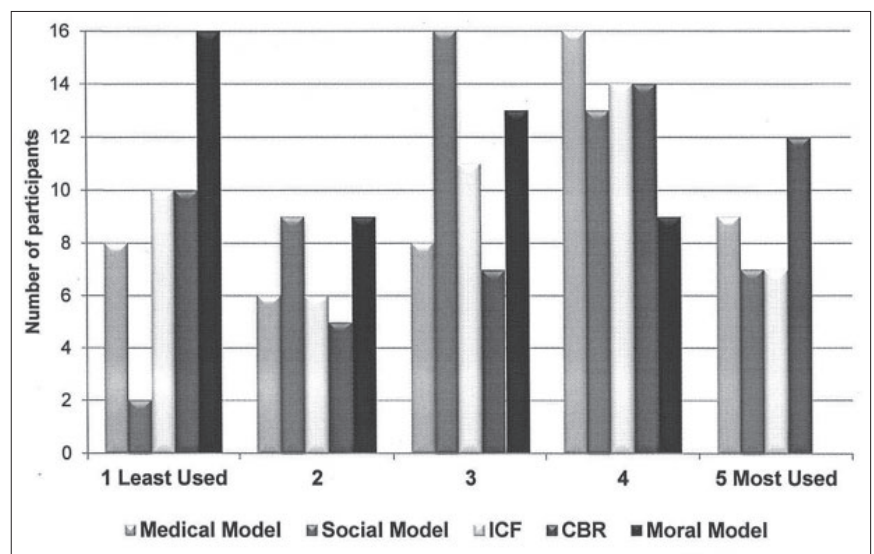

Figure I: Use of Service Delivery Models by occupational therapists in primary health care in South Africa $(n=72)$ 
(8\%); and they all worked in multidisciplinary teams (MDT).

The respondents reported using a combination of service delivery models, with $\mathrm{CBR}$ and the medical model being the most commonly used and the moral model the least used in occupational therapy at PHC level (Figure I page 48).

The interventions frequently employed by occupational therapists (Figure 2 below) included client self-management, case management and clinic-based management, while the least used interventions were shared care, outreach to neighbouring communities and home visit to clients' homes.

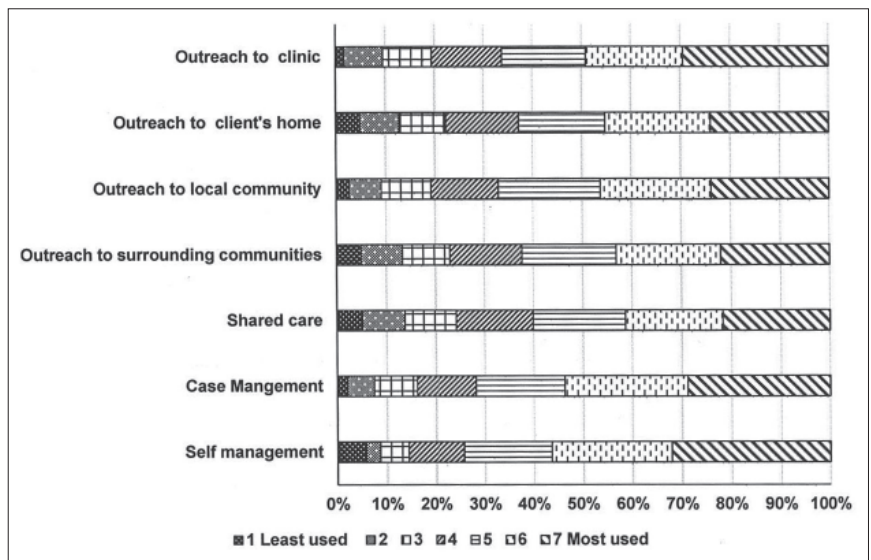

Figure 2: Intervention strategies used by occupational therapist to deliver services at the primary health care level in South Africa

\section{Phase 2 - The perceptions of occupational therapists on the integration of occupational therapy services in the PHC reengineering streams of the NHI}

A more in-depth exploration of the perceptions of five occupational therapists with experience of working in $\mathrm{PHC}$ on the integration of occupational therapy services yielded the emergent themes, sub-themes and categories shown in Figure 3 below.

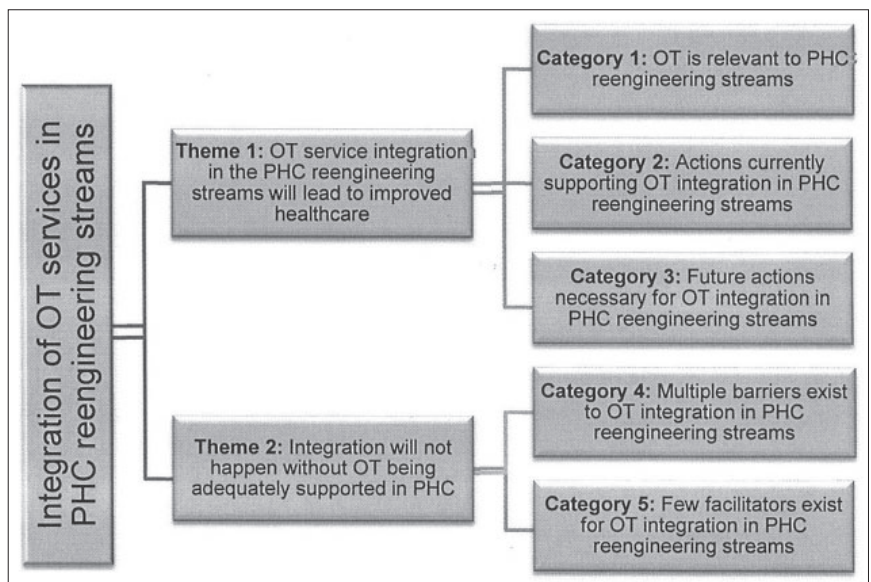

Figure 3: Themes and sub-themes/categories

Theme I - Occupational therapy service integration in the PHC reengineering streams will lead to improved healthcare

This theme had three categories.

Category I: Occupational therapy is relevant to PHC reengineering streams

While the participants felt that occupational therapy services are essential in $\mathrm{PHC}$ for the benefit of clients, there was concern about policy implementation and the present state of the underestimation of occupational therapy profession by the $\mathrm{NoDH}$.

$* \quad$... there is a vital role that an occupational therapist can play in providing health care services on a very ground level (claps hands), first line of care practitioner. (ROI)

Further exploration during the in-depth interviews supported the notion of occupational therapy as an essential component in the $\mathrm{PHC}$ reengineering streams, as indicated in the responses to the open-ended questions in the first phase such as OT is a highly valuable service for persons with disabilities especially on a primary health care level. The occupational therapists working at PHC level in South Africa strongly emphasised their perception of the relevance of occupational therapy in the $\mathrm{PHC}$ reengineering streams due to its versatility. The occupational therapists also felt that occupational therapy is essential to improve health outcomes especially for PWDs because it connects with and involves the community.

* People underestimate occupational therapy; the knowledge that occupational therapists have with regards to pathologies and how to empower people with use of occupations. (R03)

Category 2: Actions currently supporting occupational therapy integration in $\mathrm{PHC}$ reengineering

The study participants described the following actions engaged in by occupational therapists at the $\mathrm{PHC}$ level to integrate their services in the $\mathrm{PHC}$ reengineering streams as being through municipal wardbased PHC outreach teams, school health services and contracting the services of private health practitioners include: involvement in school service provision; client self-management, case management and health center visits.

$* \quad$... and the other way that we are trying to do it [integration of occupational therapy services in $\mathrm{PHC}]$ is to visit centres within the community be it adult centres, disability centres, centres for children. So that is how we are trying to implement reengineering.( R02)

This should include increasing awareness and enlightenment of other members of the MDT, managers, government, and community members about occupational therapy. One participant was involved in the dissemination of statistics in PHC to managers and other role players at meetings through documentation. She developed an Allied Health Tick Register (AHTR) which captured services provided under the following areas: mother and child, school health, mental health HIV, TB, acute, chronic, case management, and assistive devices. (ROI)

$\star \quad$... so one of the things that I did and implemented at the facility that I worked was an allied health tick register, something similar to what the nurses at the clinic did as a patient tick register to be able to show our visibility of the services we did deliver. Even just on a monthly outreach basis. Because they kind of had this attitude of, 'we come in and we unsettle the rhythm for one day', and of course we can only deliver that service again the next month when there's an outreach. ROI

The tick register could be an answer for the national identifier data sets on rehabilitation services in PHC. The register has since undergone revision and refinement and has been adopted for use by the Free State Department of Health in the Xhariep District.

* ... the payoff from this register (AHTR) is already that another OT is being placed in the [...] district with an audiologist because the services was just so visible that they said we need to place one there again. (ROI)

Category 3: Future actions necessary for Occupational Therapy integration in PHC reengineering stream

The participants emphasised awareness, outreach, screening, and health promotion as pertinent for occupational therapy service integration in $\mathrm{PHC}$ reengineering streams. 
$\$ \quad$... so really getting out into the community. Going from door to door or having events at a field somewhere where people can come and get screened where health promotions talks. I think that would be ideal rather than sitting in an office and waiting for people to come to you, I think that would be ideal. R04

Although occupational therapists strive to integrate their services into the $\mathrm{NHI} \mathrm{PHC} \mathrm{reengineering} \mathrm{streams,} \mathrm{a} \mathrm{number} \mathrm{of} \mathrm{bar-}$ riers are currently limiting the integration which were supported by the second Theme.

\section{Theme 2 - Integration will not happen without Occupational Therapy being adequately supported in PHC}

The first category under this theme was - Multiple barriers exist to occupational therapy integration in PHC reengineering streams and these described by the occupational therapists, included lack of financial, space, and transportation resources as well as a shortage of occupational therapists employed at PHC, leading to work overload and lack of recognition. Similarly, a dearth of $\mathrm{PHC}$ practice guidelines and research evidence on occupational therapy services provided in PHC were also seen as barriers. The participants felt that there was a lack of knowledge about occupational therapy by other health professionals, among policy makers, managers, patients, and the community at large.

* Lack of resources; sometimes there is a point where you can't treat anymore, you need more resources and that's also been a very big problem. R03

$\leftrightarrow \quad$... the second thing [barrier] would probably be lack of research within the OT field so just proving the benefit of our profession? R04

* When you go on your campaigns and you do workshops, explaining what OT does, then most doctors actually say oh that's what they thought physios do; which is just sad. R05

Lack of policy support especially with policy implementation and data regarding PHC occupational therapy services was also a concern.

$\rightarrow \quad$... I find it quite challenging that we are such an essential part of primary healthcare, but we are not recognised in the official documents ..., because look at the primary healthcare reengineering policy of 2010 that we have. We are not stated in that policy so that influences where your services go. R02

The second category in Theme 2 was Few facilitators exist for OT integration in PHC reengineering streams and participants felt that the facilitators that support integration of occupational therapy services in PHC reengineering streams of the $\mathrm{NHI}$ included advocacy groups amongst rehabilitation health professionals, compulsory community service for recent graduates of health professions in South Africa, as well as an awareness of the role of occupational therapy among community health workers and other community based organisations.

* I think com serve also is a great support structure. Community service - where OTs are kind of forced into primary healthcare settings. R04

* ... your community healthcare workers who are part of the wardbased outreach teams, they are the people who most of the times meet your patients first. And if they know that the service is available and if there's a referral pathway that they are aware of, they can easily transfer patients. R02

* ... usually when you make sure that you are known and as an occupational therapist and you support management, management tends to support you, so it has like this, feed forward feedback thing. R03

They also reported facilitators such as the commitment and resourcefulness of occupational therapists themselves to provide quality service as well as the knowledge of occupational therapy roles in the PHC setting by occupational therapists and other stakeholders where occupational therapy services exist. Other facilitators include, continued occupational therapy engagement with stakeholders and a cordial relationship between the occupational therapists and the MDT, and establishing mutual support between the occupational therapists and the management structures.

\section{DISCUSSION}

The demographic characteristics of the participants were in tandem with previous studies among occupational therapists in South Africa ${ }^{54,55}$. In terms of the service delivery models, the findings from this study are in contrast with majority of evidence regarding the models used by occupational therapists at the PHC level in South Africa. Previous studies indicated a dominance of the institution-based medical model among therapists with only a few using CBR ${ }^{12,39,49}$. This may be because of the previous studies only focused on a particular district or province, whereas this study involved a nation-wide survey. While the increase in the alignment of occupational therapy services in PHC with the CBR approach, biopsychosocial model and the ICF is encouraging it is possible that the $42 \%$ of participants based at district hospitals may still be working within an MDT following the medical model even when providing outreach services.

Although self-management was the most frequently used intervention strategy reported there is currently no evidence supporting its use locally. This strategy may well have been adopted by the participants since self-management has been shown to enhance quality of life, participation in desired activities, and self-efficacy among clients $^{56}$ which encompasses the occupational therapy philosophy and process outcomes ${ }^{57}$. The use of community-based management through CBR utilised in occupational therapy service provision is positive as it supports promoting health outcomes on a long-term basis to a set of scheduled patients in the community ${ }^{25,26}$. Conversely, in is of concern that the least used intervention strategies are shared care, outreach, and home visits. Home visits in particular allow the therapist to gain an understanding of the client's context, barriers in the client's home or local community and may prevent or reduce admissions to health care institutions. This finding could be due to the lack of resources available to occupational therapists working in $\mathrm{PHC}$ for the implementation of these interventions. Community health workers or caregivers are appointed on the $\mathrm{PHC}$ level to address outreach, conduct home visits and improve access to health care ${ }^{58}$. Studies in South Africa have called for an increased collaboration between occupational therapists and community health workers or rehabilitation workers ${ }^{3,49}$ as this is considered important in achieving these intervention strategies. It is recommended that these health workers be specifically trained to assist with rehabilitation services ${ }^{40}$.

Findings from the two phases of the study showed that the integration of occupational therapy services in the $\mathrm{PHC}$ reengineering streams of the $\mathrm{NHI}$ should be considered essential to improve the health outcomes of the population and reduce the overall healthcare cost and growing burden of non-communicable diseases in South Africa. The participants concern about policy implementation and the present state of the underestimation of occupational therapy services reinforces the previous findings on the importance of occupational therapy being an integral part of $\mathrm{PHC}^{13,16,17,45}$ through the holistic approach. Issues that affect clients' occupational performance should be addressed though activities and strategies to support their value system, habits, and routines within their family and community context to promote health and wellbeing ${ }^{59}$.

When actions currently supporting occupational therapy integration in $\mathrm{PHC}$ reengineering were reported on, initiatives such as the Allied Health Tick Register (AHTR) register has the potential to answer the call for a PHC-specific measure of service outputs to show the visibility and relevance of occupational therapy services in PHC. This register is the type of initiative that could ultimately support the integration of occupational therapy services with the existing PHC services. The register meets a need which is emphasised consistently in the literature for such PHC-specific measures 
of service outputs to be developed ${ }^{58,59}$ to disseminate effects of occupational therapy intervention, needs and statistics for services offered at PHC level to managers and other role players at meetings and through documentation.

The perceived barriers to the integration of occupational therapy services into the NHI PHC reengineering streams, including lack of policy implementation were similar to those reported with previous findings ${ }^{16,56,60}$. Poor resources and the lack of adequate staffing is supported by other studies on the public health care services in South Africa ${ }^{3,12}$. This is also affected by the poor retention of community service therapists at a PHC level due to a lack of posts resulting in poor continuity of occupational therapy services ${ }^{54}$. The lack of knowledge about occupational therapy is consistent with the findings of various other South African studies ${ }^{3,12,13}$. This is supported by Scriven and Atwal ${ }^{61}$ who indicted that occupational therapists must become an active part of promoting their role in primary health care making others aware of their contribution at the level of health care emphasizing the importance of occupation in health ${ }^{59}$. The lack of knowledge can be associated with the lack of research evidence for the effectiveness and outcomes achieved at the PHC level by occupational therapists ${ }^{60,62}$. Despite these barriers, the participants highlighted some facilitators that support integration of occupational therapy services in $\mathrm{PHC}$ reengineering streams of the NHI. These facilitatory strategies such as involvement with policy makers, exposing others in $\mathrm{PHC}$ to occupational therapy services as is done in community service placements and providing a good service has been shown to enable the integration of occupational therapy services in $\mathrm{PHC}$ internationally ${ }^{14,53,63,64}$

\section{Limitations of the study}

The limitations of this study include the restriction of study participants to occupational therapists who practice in PHC without recruiting other pertinent stakeholders such as other MDT members, policy makers, managers, patients, and the community. However, this was beyond the scope of this study given the time constraints associated with completing the research. Hence, it is recommended that this should be explored in future. Also, the survey did not capture the exact provinces from which participants came which may limit the generalisation of the findings. The use of an electronic survey to gather data in the first phase of this study may have limited the participation of occupational therapists in PHC who may not readily have access to the internet, particularly in the more remote areas of South Africa.

\section{CONCLUSION}

Despite the lack of clarity in recent policies on the integration of occupational therapy services at PHC level in South Africa, occupational therapists working in $\mathrm{PHC}$ recognise the relevance of occupational therapy in the $\mathrm{PHC}$ reengineering streams. More barriers than facilitators were identified by the participants and they had the opinion that, in order for occupational therapy to be successfully integrated into PHC, adequate support such as financial, space, and transport resources as well as, adequate implementation and inclusion of occupational therapy in relevant policy documents and an increase in the number of occupational therapists employed at $\mathrm{PHC}$ level, are required. Furthermore, strategies such as adequate knowledge of the role of occupational therapy in $\mathrm{PHC}$ by occupational therapists, other MDT members, policy makers, managers, patients, and the community through inter-professional training in medical schools, PHC facility- and community-based seminars, and workshops; presence of $\mathrm{PHC}$ guidelines; adequate research evidence on occupational therapy services provided in PHC; and effective retention strategy for the community service programme are required to support the integration of occupational therapy services at PHC level in South Africa.

\section{RECOMMENDATIONS}

It is recommended that occupational therapists should continue to utilise CBR, the ICF, and the social model to drive intervention at the
$\mathrm{PHC}$ level. Also, there is a need for updated $\mathrm{PHC}$ practice guidelines for occupational therapy practice in PHC. Not only will the use of $\mathrm{PHC}$ practice guidelines ensure uniformity in service delivery, it will also assist with role clarification and aligning occupational therapy services with the existing $\backslash \mathrm{PHC}$ programmes, such as mother and child, school health, mental health, HIV, TB, acute, chronic, case management, and assistive devices. The use of the AHTR or a similar checklist nationwide will also help in aligning occupational therapy services with the existing Department of Health PHC programmes. Furthermore, occupational therapists, through professional associations such as OTASA and RuReSA should continue to work with policymakers and high-level healthcare decision making structures to ensure that policy makers engage with all the pertinent health professions during policy drafting and implementation.

Continuous awareness of the role of occupational therapy at the $\mathrm{PHC}$ level, outreach programmes, and promotion of occupationbased health should be carried out. Health promotion activities and outreach programmes can be facilitated by establishing a mutual support between the occupational therapists and the community health workers. Finally, the integration of inter-professional practice and care as part of the education system should also be researched.

\section{ACKNOWLEDGEMENT}

The author acknowledges the co-authors, the study participants, and all who contributed to the success of this research and the Faculty of Health Sciences at the University of Witwatersrand for an Endowment Grant.

\section{REFERENCES}

I. Statistics South Africa. Profile of persons with disabilities in South Africa. Census. 201 I. Available from:

https://www.statssa.gov.za/publications/Report-03-01-59/Report-03-0I-5920 I I.pdf

2. Statistics South Africa. Mid-year population estimates 2018. http://www.statssa.gov.za/?p= | |34 |

3. Naidoo D, van Wyk J, Joubert R. Community stakeholders' perspectives on the role of occupational therapy in primary healthcare : Implications for practice. African Journal of Disability. 20 17;6: I-I2. https://dx.doi.org/10.4102\%2Fajod.v6i0.255

4. Occupational Therapy Association of South Africa. Occupational Therapy Assocation of South Africa (OTASA) Position Statement on Rehabilitation. South African Journal of Occupational Therapy. 2017; 47(2): 53-55.

5. National Department of Health. Framework and Strategy for Disability and Rehabilitation Services in South Africa 2015-2020. 20I5; 3-25. Available from:

http://ilifalabantwana.co.za/wp-content/uploads/20 I6/07/Framework-25-may_I_3.docx

6. Department of Health South Africa. White Paper: National Health Insurance Policy - Towards Universal Health Coverage. 20 I 7; I-67. Available from: http://www.health.gov.za/index.php/nhi

7. Republic of South Africa. National Health Insurance Bill. Government Gazette No. 42598 of 26 July 2019. Available from:

https://www.gov.za/sites/default/files/gcis_document/201908/ national-health-insurance-bill-b- I I-2019.pdf

8. National Department of Health. Provincial guidelines for the implementation of the three streams of PHC re-engineering. $20 \mathrm{II}$; I-I0. Available from:

http://www.jphcf.co.za/wp-content/uploads/2014/06/GUIDELINESFOR-THE-IMPLEMENTATION-OF-THE-THREE-STREAMS-OFPHC-4-Sept-2.pdf.

9. Paulus E. Re-engineering Primary Health Care: A National Perspective. Presented at Anova Aeroton Health Institute and Gauteng Province. 2013; Available from:

http://www.anovahealth.co.za/uploads/documents/Paulus_NDoH Anova_Conference_28022012.pdf.

10. National Department of Health (South Africa). National Health Insurance for South Africa: Towards Universal Health Coverage. White Paper. 2015; 48: I-398. Available from:

http://www.health.gov.za/index.php/nhi?download=2257: whitepaper-nhi-2017 
II. Maseko L and HB. People-centeredness in health system reform . Public perceptions of private and public hospitals in South Africa. South African Journal of Occupational Therapy. 20 18; 48(I): 22-27. http://dx.doi.org/I0.17/59/23 I0-3833/2017/vol48n la5

12. Ned L, Cloete L, Mji G. The experiences and challenges faced by rehabilitation community service therapists within the South African Primary Healthcare health system. African Journal of Disability. 20 I 7; 6(0): I-II. https://doi.org/10.4102/ajod.v6i0.31।

13. Misbach S. The implementation of the rehabilitation service package in the Metropole Health District, Western Cape Province, South Africa. Unpublished thesis. University of the Western Cape; 2004.

14. Donnelly CA, Leclair LL, Wener PF, Hand CL, Letts LJ. Occupational therapy in primary care: Results from a national survey. Canadian Journal of Occupational Therapy. 2016: 135-142. https://doi.org/10.1/77/0008417416637|86

I5. Dahl-Popolizio S, Rogers O, Muir SL, Carroll J, Manson L. Interprofessional Primary Care: The Value of Occupational Therapy. The Open Journal of Occupational Therapy. 2017; 5(3). https://doi.org/10.15453/2168-6408.1363

16. Myezwa H, Van Niekerk M. National Health Insurance implications for rehabilitation professionals and service delivery. South African Journal of Physiotherapy. 2013; 69(4): 3-9. https://doi.org/10.4102/sajp.v69i4.372

17. Roberts P, Farmer ME, Lamb AJ, Muir S, Siebert C. The Role of Occupational Therapy in Primary Care. The American Journal of Occupational Therapy. 2014; 68(3): S25-S33. https://doi.org/10.5014/ajot.2014.686S06

18. Vergunst R, Swartz L, Hem KG, Eide AH, Mannan H, MacLachlan $M$, et al. Access to health care for persons with disabilities in rural South Africa. BMC Health Services Research. 2017; $17(1)$. https://dx.doi.org/I0. I 186\%2Fs I 29I3-017-2674-5

19. Mulumba M, Nantaba J, Brolan CE, Ruano AL, Brooker K, Hammonds R. Perceptions and experiences of access to public healthcare by people with disabilities and older people in Uganda. International Journal for Equity in Health. 2014; Oct. https://doi.org/10.1 I86/s I 2939-0|4-0076-4

20. Hussey M, MacLachlan M, Mji G. Barriers to the Implementation of the Health and Rehabilitation Articles of the United Nations Convention on the Rights of Persons with Disabilities in South Africa. International Journal of Health Policy and Management. 2016. https://dx.doi.org/10.15171\%2Fijhpm.2016.117

21. Coovadia H, Jewkes R, Barron P, Sanders D, Mclntyre D. The health and health system of South Africa: historical roots of current public health challenges. The Lancet. 2009; 374(9692): 817-834. https://doi.org/I0.1016/S0140-6736(09)6095I-X

22. Mayosi BM, Benatar SR. Health and Health Care in South Africa - 20 Years after Mandela. The New England Journal of Medicine. 2014; 37I(I4): I344-I353. https://doi.org/I0.1056/NEJMsr 1405012

23. World Health Organisation. World Health Statistics 2019. Monitoring health for the SDGs. [Online] World Health Organization. 2019. Available at:

https://www.who.int/gho/publications/world_health_statistics/2019/ EN WHS 2019 TOC.pdf

24. Pillay $\mathrm{Y}$, Barron $\mathrm{P}$. The implementation of $\mathrm{PHC}$ re-engineering in South Africa. Public Health Association of South Africa. 201 I; I-6. Available from: https://www.phasa.org.za/wp-content/uploads/20 I I/ I I/Pillay-The-implementation-of-PHC.pdf.

25. Bheekie A, Bradley H. Re-engineering of South Africa's primary health care system: where is the pharmacist? South African Family Practice. 2016; 58(6): 242-248. https://doi.org/10.1080/20786/90.2016.1/86365

26. McColl MA, Shortt S, Godwin M, Smith K, Rowe K, O'Brien P, et al. Models for Integrating Rehabilitation and Primary Care: A Scoping Study. Archives of Physical Medicine and Rehabilitation. Elsevier Inc.; 2009; 90(9): 1523-1531. https://doi.org/10.1016/j.apmr.2009.03.017

27. World Health Organisation. A Strategy for Rehabilitation, Equalization of Opportunities, Poverty Reduction and Social Inclusion of People with Disabilities: Joint Position Paper. WHO Library Cataloguing-in-Publication Data. 2004. Avaiable at:

h t t p s : / / a p p s. who.int/iris / bit s t rea m/han dle/I0665/43060/924I592389_eng.pdf;jsessionid=BE358F79/39
3D9685429684609E3E IB3?sequence $=$ I

28. Govender K, Christopher C, Lingah T. The role of the occupational therapist in case management in South Africa. South African Journal of Occupational Therapy. 2018; 48(2): 12-19. http://dx.doi.org/10.17159/23103833/2018/vol48n2a3

29. Kennedy A, Bower P, Reeves D, Blakeman T, Bowen R, ChewGraham C. Implementation of self management support for long term conditions in routine primary care settings: cluster randomised controlled trial. BMJ. 20I3; I-II.

https://doi.org/10.I 136/bmj.f2882

30 Levitt JM. Exploring how the social model of disability can be reinvigorated: in response to Mike Oliver. Disability and Society. 20 I 7; 32(4): 589-594. https://doi.org/10.1080/09687599.2017.1300390

31. Degener T. A New human rights model of disability. In: Fina V Della, Cera R, Palmisano G (eds.) The United Nations convention on the rights of persons with disabilities: A commentary. Springer, Cham, Switzerland; 2017: 41-60.

32. Wade D. Rehabilitation-a new approach. Part four: A new paradigm, and its implications. Clinical Rehabilitation. 2016; 30(2): 109-II8. https://doi.org/10.II77/026921551560I I77

33. World Health Organization. International Classification of Funcitoning, Disabiltiy and Health: Short version. WHO, Geneva. 200I.

34. Eerola M. Representations of Disability within Occupational Therapy Literature - A discourse analysis. unpublished thesis. Norwegian University of Science and Technology; 2012.

35. Retief M, Letsosa R. Models of disability: A brief overview. HTS Theological Studies. 2018; 74(I): I-8. http://dx.doi.org/10.4102/hts.v74il .4738

36. National Department of Health, National Rehabilitation Policy. Pretoria: Government Press, 2000

37 United Nations. United Nations Convention on the Rights of Persons with Disabilities. (UNCRPD) New York: UN, 2006. Available at: https://www.un.org/development/desa/disabilities/convention-onthe-rights-of-persons-with-disabilities.html

38. Sherry K. Disability and rehabilitation: Essential considerations for equitable, accessible and poverty-reducing health care in South Africa. South African Health Review. 2014/2015. 2015; 89-100.

39. Mji G, Rhoda A, Statham S, Joseph C. A protocol for the methodological steps used to evaluate the alignment of rehabilitation services in the Western Cape, South Africa with the National Rehabilitation Policy. BMC Health Services Research. 2017; I7(I): I-I I. https://doi.org/10.1|86/s|29|3-017-214|-3

40. Lorenzo, T., Van Pletzen, E., \& Booyens MG. Determining the competencies of community based workers for disability-inclusive development in rural areas of South Africa, Botswana and Malawi. The International Electronic Journal of Rural and Remote Health Research. Education Practice and Policy. 2015; I5(29|9): I-I4. Available from: http://www.rrh.org.au

4I. Mannan H, McVeigh J, Amin M, MacLachlan M, Swartz L, Munthali A, et al. Core Concepts of Human Rights and Inclusion of Vulnerable Groups in the Disability and Rehabilitation Policies of Malawi, Namibia, Sudan, and South Africa. Journal of Disability Policy Studies. 2012; 23(2): 67-81. https://doi.org/10.I I 77//10442073/2439103

42. M'kumbuzi VRP, Myezwa H. Conceptualisation of community-based rehabilitation in South Africa: A systematic review. South African Journal of Physiotherapy. 2016; 72(I): I-8. https://dx.doi.org/10.4102\%2Fsajp.v72il.30।

43. Dalinjong PA, Welaga P, Akazili J, Kwarteng A, Bangha M, Oduro A, et al. The association between health insurance status and utilization of health services in rural Northern Ghana: Evidence from the introduction of the National Health Insurance Scheme. Journal of Health, Population and Nutrition. 2017; 36(42): I-I0. https://dx.doi.org/10.1 186\%2Fs4 I043-017-0128-7

44. Canadian Association of Occupational Therapists. CAOT Position Statement: Occupational Therapy in Primary Care. 20I3. Available at https://caot.in I touch.org/document/3710/O\%20-\%200T\%20 in\%20Primary\%20Care.pdf

45. Occupational Therapy Association of South Africa. Occupational Therapy Association of South Africa (OTASA) Position Statement on Occupational Therapy Primary Health Care. South African Journal of Occupational Therapy. 2015; 45(3): 58-59. http://dx.doi.org/I0.17159/23 I0-3833/2015/v45n3/al I 
46. Creswell JW. Research Design: Qualitative, Quantitative and Mixed Approaches. 3rd Edition. Thousand Oaks. CA, US: Sage Publications, Inc; 2009.

47. Fetters MD, Freshwater $D$. The I + I = 3 Integration Challenge. Journal of Mixed Methods Research. 2015; 9(2): II5-II7. https://doi.org/I0. I I 77\%2FI5586898I558I 222

48. Teddlie C, yu F. Mixed Methods Sampling: A Typology With Examples. Journal of Mixed Methods Research. 2007; I(I): 77-I00. https://doi.org/I0. I I 77\%2F I558689806292430

49. Naidoo D, Van Wyk J, Joubert RWE. Exploring the occupational therapist's role in primary health care: Listening to voices of stakeholders. African journal of primary health care \& family medicine. 20 I6;8(I): el-e9. http://dx.doi.org/l 0.4 I02/phcfm.v8il I I 39

50. Bartlett JE, Kotrlik JW, Higgins CC. Organizational Research: Determining Appropriate Sample Size in Survey Research. Information Technology, Learning, and Performance Journal. 200 I; I9(I): 43-50.

5I. Harris PA, Taylor R, Thielke R, Payne J, Gonzalez N, Conde JG. Research Electronic Data Capture (REDCap) - A metadata-driven methodology and workflow process for providing translational research informatics support. Journal of Biomedical Informatics. 2009; 42(2): 377-38I. https://doi.org/10.1016/j.jbi.2008.08.010.

52. TIBCO Statistica ${ }^{\text {TM }}$ Statistica version I3-2 Available from: http://software.dell.com/products/statistica/

53 Curtin M, Fossey E. Appraising the trustworthiness of qualitative studies: Guidelines for occupational therapists. Australian Occupational Therapy Journal. 2007 54(2): 88-94.

https://doi.org/I0. I I I I/j. |440-1630.2007.0066 I.x

54. van Stormbroek K, Buchanan H. Community Service Occupational Therapists: thriving or just surviving? South African Journal of Occupational Therapy. 2016; 46(3): 63-72.

http://dx.doi.org/I0.17159/23103833/2016/v46n3al I

55. Monareng LL, Franzsen D, van Biljon H. A survey of occupational therapists' involvement in facilitating self-employment for people with disabilities. South African Journal of Occupational Therapy. 2018 ; 48(3): 52-57.

http://dx.doi.org/10.17/59/2310-3833/2017/vol48n3a8

56. Richardson J, Loyola-Sanchez A, Sinclair S, Harris J, Letts L, Maclntyre NJ, et al. Self-management interventions for chronic disease: A systematic scoping review. Clinical Rehabilitation. 2014; 28(I I): I067-I077. https://doi.org/10.1 I77\%2F02692 I55 |4532478

57. Garvey J, Connolly D, Boland F, Smith SM. OPTIMAL, an occupational therapy led self-management support programme for people with multimorbidity in primary care: A randomized controlled trial. BMC Family Practice. 2015; I6(I): I-II. https://doi.org//0.II77\%2F02692I55|4532478

58. Caregivers Action Network. Community Caregivers: The Backbone for Accessible Care and Support. 2013. Avaiable at: https://www.hst.org.za/publications/NonHST\%20 Publications/29223-20 I 30902 I 80407-SA\%20Report\%20CAN\%20 16\%20August\%202013.pdf

59. Dahl-Popolizio S, Doyle S, Wade S. The role of primary health care in achieving global healthcare goals: Highlighting the potential contribution of occupational therapy. World Federation of Occupational Therapists Bulletin. 2018; 3828. https://doi.org//0.1080/|4473828.2018.|433770

60. Dizon JM, Grimmer KA, Machingaidze S, Louw QA, Parker H. South African primary health care allied health clinical practice guidelines: The big picture. BMC Health Services Research. 2018; I8(I): I-I3. https://dx.doi.org/10.I 186\%2Fs I 2913-018-2837-z

61. Scriven A, Atwal A. Occupational therapists as primary health promoters: Opportunities and barriers. British Journal of Occupational Therapy. 2004 Oct; 67(10): 424-9.

62. Pitout H. Research Orientation of South African occupational therapists. South African Journal of Occupational Therapy. 20I3; 43(2): 5-II.

63. Dahl-Popolizio S, Muir SL, Davis K, Wade S, Voysey R. Occupational Therapy in Primary Care: Determining Receptiveness of Occupational Therapists and Primary Care Providers. The Open Journal of Occupational Therapy. 2017; 5(3) Article 10. https://doi.org/10.15453/2168-6408.1372

64. Koverman B, Royeen L, Stoykov M. Occupational Therapy in Primary Care: Structures and Processes that Support Integration. The Open Journal of Occupational Therapy. 2017;5(3): Article 12 https://doi.org/10.15453/2 168-6408.1376

\section{AUTHOR CONTRIBUTIONS}

* Anthony Jejelaye - Postgraduate student - conceptualisation and completion of project and article manuscript.

* Lebogang Maseko - supervisor of MSc project - helped with the conceptualisation and guidance for completion of project.

* Denise Franzsen - supervisor of MSc project - helped with the conceptualisation and guidance for completion of project.

\section{Corresponding Author}

Anthony Jejelaye

Email: jejelayeanthony@gmail.com 